\title{
Gêneros discursivos: conceitos e desenvolvimentos teóricos
}

\author{
The genre: concepts and theoretical developments \\ Géneros discursivos: conceptos y desarrollos teóricos
}

Recebido: 05/02/2021 | Revisado: 11/02/2021 | Aceito: 15/02/2021 | Publicado: 22/02/2021

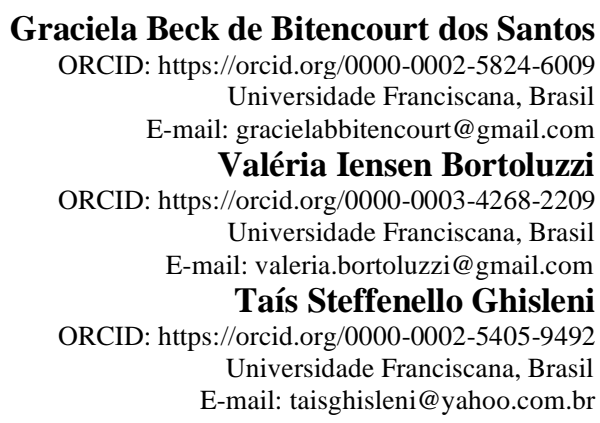

\begin{abstract}
Resumo
Com sua origem nas últimas três décadas do século XX, sob forte influência da revolução tecno-linguística, surge uma linguagem de natureza enunciativa com mais semioses do que usualmente, trazendo consigo, uma variada gama de gêneros discursivos, permeados por arranjos sociais, com diferentes características composicionais e propósitos comunicativos. É por meio dos gêneros discursivos que a comunicação é estabelecida através da língua. A partir de uma pesquisa bibliográfica, este artigo tem como objetivo apresentar semelhanças e distinções entre as diversas abordagens de teorias de gêneros abarcando, em especial a teoria de Bakhtin (1997), a abordagem sociossemiótica de Hasan (1995), Martin (1984) e Kress (1997) e a abordagem sociorretórica de Swales (1990), Miller (1994) e Bazerman (1994). A partir deste trabalho foi possível estabelecer um paralelo, considerando os desenvolvimentos teóricos sobre os gêneros discursivos cunhado por diferentes autores e os conceitos que vêm enriquecendo as pesquisas na área da Linguística e da Linguística Aplicada. Essa discussão teórica, apresenta-se dividida em duas seções sendo a primeira sobre o conceito e a segunda sobre os desenvolvimentos teóricos acerca das perspectivas de gêneros discursivos.
\end{abstract}

Palavras-chave: Gêneros discursivos; Sociorretórica; Sociosemiótica; Teorias.

\begin{abstract}
Originated in the last three decades of the $20^{\text {th }}$ century, tightly influenced by the techno-linguistics, an enunciative language emerges with more semiosis than it was before, bringing with it a varied range of genres, permeated by social arrangements, with different compositional characteristics and communicative purposes. By the genre that the communication is stablished by the language. From a bibliographic research, this article has as the mainly purpose to clarify the similarities and distinctions among the different genre theory encompassing specially the theory of Bakhtin (1997), the sociosemiotic approach from Hasan (1995), Martin (1984) and Kress (1997) and the socio-rhetoric approach from Swales (1190), Miller (1994) and Bazerman (1994). From this research on, it was possible to stablish a parallel considering the theoretical developments of genre coined by different authors and the concepts that have been enriching the researches in the Linguistic and Applied Linguistics. This theoretical discussion is divided in two sections, being the first about the concept and the second about the theoretical developments about the genre perspectives.
\end{abstract}

Keywords: Genre; Sociosemiotic; Sócio-rhetoric; Theories.

\section{Resumen}

Con sus origenes en las últimas trés décadas del siglo XX, con fuerte influenza de la revolución tecnológica de natureza enunciativa con más semioses que usualmente, trayendo junto, una gran cantidad de géneros discursivos, entremeados por sugeréncias sociales, con distintas características composicionales y propósitos comunicativos. Es por medio de los géneros discursivos que la comunicación es estabelecida a través de la lengua. Siguiendo una búsqueda bibliográfica, este artículo tiene como objetivo presentar semejanzas y distinciones entre las diversas teorías de géneros, en especial la teoría de Bakhtin (1997) la teoría sociossemiótica de Hasan (1995), Martin (1984) y Kress (1997) y la teoría sociorretórica de Swales (1990), Miller (1994) y Bazerman (1994). A partir de ese trabajo fue posible establecer un paralelo, considerando los desarrollos teóricos sobre los géneros discursivos de acuerdo con diferentes autores e conceptos que vienen mejorando las búsquedas en la área de la Linguística y la Linguística 
Aplicada. Esa discusión teórica, se presenta dividida en dos secciones siendo la primera sobre los conceptos y la segunda sobre los desarrollos teóricos de las perspectivas de géneros discursivos.

Palavras clave: Géneros discursivos; Sociorretórica; Sociossemiótica; Teorías.

\section{Introdução}

A linguagem é a capacidade humana de articular significados coletivos através de sistemas arbitrários de representação de sentidos, é imprescindível para a comunicação ser estabelecida estando presente nos diversos convívios sociais com a finalidade de interação comunicacional.

A comunicação, especificamente realizada pela fala se apresenta, como uma atividade inerente ao ser humano e, por conta disso, o homem está atrelado à linguagem. É por meio da linguagem que os sujeitos falam, escrevem, interpretam, exprimem sentimentos, opiniões, interagem em situações que encontram no cotidiano e se tornam capazes de conhecer sua cultura, o meio onde vivem e seu papel social.

Permeado pela globalização, o século XXI tem sido palco para o aparecimento de novas formas de comunicação, as tecnologias da informação e comunicação emergem nesse tempo culturalmente diversificado onde a escola vem tentado se adequar, fazendo frente às demandas da sociedade do conhecimento.

Essa era da inovação, indubitavelmente intervém em vários aspectos do cotidiano da vida moderna, propiciando o aparecimento de novas formas de comunicação, caracterizadas pela agilidade e praticidade em que ocorrem, independentemente das limitações temporais e geográficas. Surge, assim, uma linguagem fortemente influenciada pela tecnolinguística, caracterizada como um "sistema de sinais vocais" (Berger, P. L. \& Luckmann, 2003, p. 56) através dos quais a comunicação se estabelece.

Ferreira (2015, p. 80) traça um percurso por três importantes revoluções tecno-linguísticas na história: a escrita, a gramaticalização e a mecanização da linguagem. Com sua origem nas últimas três décadas do século XX, sob forte influência da revolução tecno-linguística, surge uma linguagem de natureza enunciativa com mais semioses do que usualmente, trazendo consigo, uma variada gama de gêneros discursivos com diferentes características composicionais e propósitos comunicativos.

De acordo com Bazerman, Bonini e Figueiredo:

Um mundo unido pela comunicação e pelo conhecimento, construindo uma cooperação cada vez mais complexa em diversos níveis, coloca uma demanda crescente sobre os gêneros que partilham nossos significados e nosso conhecimento, coordenam nossas ações e mantêm coesas nossas instituições. Um mundo em transformação por novas tecnologias e mídias, bem como por novos arranjos sociais e econômicos requer a transformação rápida e profunda dos gêneros. Em um mundo onde problemas prementes exigem níveis crescentes de coordenação e compreensão mútua, forjar gêneros efetivos é uma questão de bem-estar global. Em um mundo onde cidadãos de todas as nações precisam de graus cada vez mais elevados de participação letrada, desenvolver a competência comunicativa de todos, tornar disponíveis os gêneros do poder e da cooperação, é uma questão de capacitação e de justiça social. (Bazerman, Bonini \& Figueiredo apud Bawarshi \& Reiff, 2013, p. 18)

Em um mundo cada vez mais interconectado, emergem inúmeros gêneros discursivos, passíveis de análise sob diferentes perspectivas, compreendidas por prismas teóricos reconhecidos internacionalmente, como é o caso da abordagem sociossemiótica de Hasan, Martin e Kress e da abordagem sociorretórica de Swales, Miller e Bazerman.

Por meio de uma pesquisa bibliográfica, este artigo tem como objetivo apresentar e refletir acerca das teorias de gêneros existentes, em especial as teorias de Bakhtin, Hasan, Martin, Kress, Swales, Miller e Bazerman. Essa discussão teórica será dividida em duas seções sendo a primeira sobre o conceito e a segunda sobre os desenvolvimentos teóricos acerca das perspectivas de gêneros discursivos. 


\section{Metodologia}

O presente estudo caracteriza-se como uma pesquisa qualitativa pois considera a íntima e dinâmica relação entre o mundo real e a subjetividade do sujeito, fato que não pode ser traduzido em números. Segundo Pereira et al. (2018) "os métodos qualitativos são aqueles nos quais é importante a interpretação por parte do pesquisador com suas opiniões sobre o fenômeno em estudo".

De acordo com Prodanov e Freitas:

A interpretação dos fenômenos e a atribuição de significados são básicas no processo de pesquisa qualitativa. Esta não requer o uso de métodos e técnicas estatísticas. O ambiente natural é a fonte direta para coleta de dados e o pesquisador é o instrumento-chave. Tal pesquisa é descritiva. Os pesquisadores tendem a analisar seus dados indutivamente. O processo e seu significado são os focos principais de abordagem. Na abordagem qualitativa, a pesquisa tem o ambiente como fonte direta dos dados. O pesquisador mantém contato direto com o ambiente e o objeto de estudo em questão, necessitando de um trabalho mais intensivo de campo. Nesse caso, as questões são estudadas no ambiente em que elas se apresentam sem qualquer manipulação intencional do pesquisador. (Prodanov \& Freitas, 2013, p. 70)

A pesquisa qualitativa do tipo documental visa um levantamento de dados e, segundo Gil (2002, p. 45) embasa-se em materiais que ainda não foram analisados ou que podem ser refeitos de acordo com a finalidade da investigação proposta.

A pesquisa do tipo documental é muito vantajosa, segundo Gil:

Há que se considerar que os documentos constituem fonte rica e estável de dados. Como os documentos subsistem ao longo do tempo, tornam-se a mais importante fonte de dados em qualquer pesquisa de natureza histórica. Outra vantagem da pesquisa documental está em seu custo. Como a análise dos documentos, em muitos casos, além da capacidade do pesquisador, exige apenas disponibilidade de tempo, o custo da pesquisa torna-se significativamente baixo, quando comparado com o de outras pesquisas. Outra vantagem da pesquisa documental é não exigir contato com os sujeitos da pesquisa. É sabido que em muitos casos o contato com os sujeitos é difícil ou até mesmo impossível. Em outros, a informação proporcionada pelos sujeitos é prejudicada pelas circunstâncias que envolvem o contato. (Gil, 2002, p. 46)

Os documentos se mostram como uma rica fonte de informações, permitindo, do ponto de vista da forma de abordagem, a proposição de ideias que explorem novas perspectivas, por isso buscou-se, através de uma pesquisa documental, que, segundo Lüdke e André (1986, p. 38) é um tipo de pesquisa "pouco explorada não só na área da educação como em outras áreas das ciências sociais" apresentar uma investigação acerca dos gêneros discursivos.

\section{Conceitos de Gêneros Discursivos ${ }^{1}$}

O estudo sobre os gêneros discursivos vem desde a Antiguidade, com início na retórica clássica, em suas origens jurídicas e literárias foi sistematizada pelos gregos e consolidada pelos romanos. O termo gênero é muito utilizado na teoria literária e a partir das obras de Mikhail Bakhtin, na sociolinguística, acompanhado pelos estudos acerca da língua e do discurso, que reafirmam que essas esferas comunicativas permeiam a existência humana e nos diferencia dos demais animais.

O interessante é que essas visões divergentes sobre os gêneros se refletem na etimologia do termo genre [gênero textual], tomado de empréstimo ao francês. Por um lado, genre remonta, através do termo correlacionado gender [gênero social], ao termo latino genus, que se refere a "espécie" ou "classe de coisas". Por outro lado, genre, novamente por meio do correlato gender, pode remontar ao cognato latino gener, que significa gerar. As diversas maneiras como o termo gênero tem sido definido e usado na história refletem sua etimologia. Em diversos momentos

\footnotetext{
${ }^{1}$ Sobre as teorias de gênero, torna-se imprescindível ressaltar que diversas terminologias, entre as quais, "gênero textual" e "gênero discursivo" são utilizadas, embora o conceito de gênero seja muito próximo nas diferentes abordagens. Neste artigo adotaremos o termo "gênero discursivo, o termo "gênero textual" aparecerá apenas em citações diretas.
} 
e em diversas áreas de estudo, o termo gênero foi definido e utilizado principalmente como uma ferramenta classificatória, um jeito de dividir e organizar espécies de texto e outros objetos culturais. (Bawarshi \& Reiff, 2013, p. 16).

Os gêneros são produzidos com diferentes estruturas, assuntos e propósitos comunicativos, compreendem textos, discursos, intencionalidades e, de forma global, a própria língua. Segundo Dell’isola (2007, p. 17) “os gêneros textuais são práticas sócio históricas que se constituem como ações para agir sobre o mundo e dizer o mundo, constituindo-o de algum modo".

Com o livro "Estética da criação verbal", datado de 1952-1953, o russo Mikail Bakhtin ofereceu, em sua obra, o primeiro impulso para a compreensão de que "o gênero é socialmente situado e relevante para o discurso em todas as esferas de atividade". (Bawarshi \& Reiff, 2013, p. 259). Presentes em todas as esferas da comunicação humana, de forma oral ou escrita, com diferentes formas composicionais, os gêneros são definidos por Bakhtin (1997, p. 279) como "tipos relativamente estáveis de enunciados".

Os gêneros discursivos, necessários para a interlocução humana, são recursos sociais, orientados, considerados por Bakhtin (1997, p. 85) "as correias de transmissão que levam da história da sociedade à história da língua”. A natureza do enunciado e o propósito a que ele se destina determinam o gênero a ser produzido.

Sendo tomada como ponto de partida para os estudos do gênero, a teoria de Bakhtin não privilegia somente os gêneros literários e retóricos, pois considera a diferença fundamental entre os gêneros primários (simples) que se constituem em circunstância de uma comunicação verbal espontânea e os gêneros de discurso secundários (complexos) inferidos em uma situação comunicativa mais complexa. Segundo Bakhtin (1997, p. 281) para o processo formativo dos gêneros secundários ocorrer é necessária a absorção e transmutação dos gêneros primários (simples) para uma forma mais complexa e evoluída, normalmente escrita. Ainda, segundo Bakhtin (1997, p. 281) “a distinção entre gêneros primários e secundários tem grande importância teórica, sendo esta a razão pela qual a natureza do enunciado deve ser elucidada e definida por uma análise de ambos os gêneros".

Segundo Bawarsh e Reiff:

o gênero passou a ser definido menos como modo de organizar tipos de texto e mais como um poderoso formador de textos, sentidos e ações sociais, ideologicamente ativo e historicamente cambiante. Nessa perspectiva os gêneros são entendidos como formas de conhecimento cultural que emolduram e medeiam conceitualmente a maneira como entendemos e agimos tipicamente em diversas situações. (Bawarsh \& Reiff, 2013, p. 16)

De acordo com Marcuschi (2008) os gêneros são atividades discursivas socialmente estabilizadas que se prestam aos mais variados tipos de controle social e até mesmo o exercício do poder. A língua é um fator de interação social, assim, considerando que os gêneros estão inseridos na língua, eles são o meio para que essa interação/compreensão aconteça.

A interação verbal manifesta-se por meio dos textos orais e escritos que são fruto da ação humana em função de diferentes objetivos, interesses e contextos. Para que a função dos gêneros discursivos seja cumprida, torna-se necessária a compreensão acerca do contexto, intencionalidade, propósitos, restrições, convenções e valores de comunidade discursiva ao produzir, no papel de criador do enunciado, ou ao interpretar um texto, na função de interlocutor. A dimensão comunicativa torna-se possível por meio da linguagem "meio universal pelo qual a compreensão se realiza” (Alves, 2011, p. 24).

O estudo dos gêneros mostra o funcionamento da sociedade, abordagem essa que hoje conquistou um fecundo espaço interdisciplinar, fundamentalmente para as atividades relacionadas à linguagem, concebida como um ato social e cultural. Essas ações de ordem comunicativa, buscando atingir determinados interlocutores e objetivos, adequam-se e alteram-se dentro de um dado espaço de tempo, contexto e ocasião. 
Os gêneros podem ser compreendidos como um recurso organizador dos enunciados escritos e falados, posto que todos os textos produzidos nas diversas áreas da atividade humana, podem ser associados de acordo com suas respectivas semelhanças composicionais e socio-discursivas.

A partir dos estudos de Bakhtin, que fornece contribuições a todos os teóricos, muitas correntes/teorias/abordagens de gêneros se desenvolveram, tais como as abordagens sociossemióticas de Ruqayia Hasan, James Robert Martin e Gunther Kress e a abordagem sociorretórica de John Swales, Carolyn Miller e Charles Bazerman.

\section{Desenvolvimentos Teóricos}

Existem diferentes orientações de análise de gêneros discursivos com o propósito de entender a natureza e o funcionamento desses enunciados que estabelecem relações entre os participantes no uso da linguagem. Os teóricos estudiosos do gênero evidenciam uma ligação entre os usuários da língua e, a partir disso, supõem que todo texto produzido de maneira eficiente mostrará características do escritor, dos leitores potenciais e do contexto em que esse texto foi produzido/consumido. (Hyland, 2003, p. 21).

Dentre as orientações de análise de gêneros, destacam-se: a perspectiva Bakhtiniana, a abordagem Sociorretórica, a Nova Retórica, a Escola de Sydney e a Escola de Genebra. Especificamente, abordaremos a Escola de Sydney (perspectiva sistêmico-funcional), a abordagem Sociorretórica (English for Specific Purposes), também conhecida como Escola Britânica de ESP e a Nova Retórica ou Escola Norte-Americana.

A visão do gênero baseada na perspectiva da linguística Sistêmico-Funcional, doravante LSF, surgiu entre os anos de 1950 e 1960, a partir de estudos advindos do linguista Michael Halliday. Segundo Halliday (1985) a linguagem é um sistema de construção de significados, sendo, assim, um instrumento de interação social, com o principal propósito de estabelecer a comunicação entre interlocutores.

A gramática funcional se relaciona com as escolhas no uso da língua, feitas pelos usuários dela, em contextos sociais reais, assim, pode-se afirmar que a gramática é como um sistema de escolhas que está à disposição do falante e do escritor.

Bawarshi e Reiff eloquentemente afirmam que:

A linguística sistêmico-funcional opera a partir da premissa de que a estrutura linguística está integralmente relacionada com a função social e o contexto. A linguagem se organiza de dada maneira dentro de uma cultura porque essa organização serve a um propósito social no interior daquela cultura. Assim, o "funcional" diz respeito ao trabalho que a linguagem realiza dentro de determinados contextos. O "sistêmico" diz respeito à estrutura ou organização da linguagem, de modo que ela possa ser usada para fazer determinadas coisas dentro daqueles contextos. (Bawarshi \& Reiff, 2013, p. 47)

$\mathrm{Na}$ LSF, a linguagem é compreendida a partir de quatro importantes pontos teóricos, sendo, segundo Eggins (2004) o funcional, pelo uso da linguagem ser funcional, o semântico pois a função da linguagem é criar significados, o contextual pelo fato de que os significados são influenciados pelo contexto social e cultural em que são utilizados e o semiótico pelo processo de criação de significados através da possibilidade de diferentes escolhas.

É a partir do contexto sociocultural e das intenções do interlocutor que as escolhas linguísticas são feitas por ele, de forma consciente ou não.

Um dos princípios fundamentais da LSF é vislumbrar a linguagem a partir de uma perspectiva sociossemiótica. Primeiramente, Halliday e Hasan (1989) definem semiótica como o "estudo geral dos signos", em seguida propõem uma nova definição sendo o estudo de sistemas de signos ou o estudo dos significados. 
Os sistêmicos interessam-se em investigar como as pessoas utilizam a linguagem dentro do processo social, onde o sujeito se constitui pela variedade de interações comunicativas e pelos códigos semióticos desempenhados por ele nas comunidades em que se envolve.

A linguista Ruqayia Hasan traz como argumento central, em suas obras, a necessidade e a possibilidade de analisar a linguagem como um sistema sociossemiótico. Hassan leva em consideração o contexto de uso do gênero, as suas relações entre os significados e as formas linguísticas. A perspectiva da linguista, em conformidade com a teoria social de Bernstein e com a linguística sistêmico-funcional de Halliday compreende a linguagem como "um sistema de significações que media a existência humana". (Motta-Roth \& Eberle, 2005, p. 12).

Hassan emprega o termo texto como sinônimo de enunciado, portanto, para ela o texto é um evento social presente na linguagem e na cultura. Levando em consideração que é por meio da linguagem que os gêneros se materializam, pode-se afirmar que eles são produzidos com um determinado propósito, em diferentes situações de uso e que lhes são pertinentes as características comuns àquele contexto.

Hasan avaliou a variação sociossemântica da linguagem de acordo com a atividade social dos sujeitos que a utilizam. Para a autora, por meio da particularidade do contexto é possível prever os elementos de um texto, podendo ser elementos obrigatórios (que devem ocorrer), elementos opcionais (que podem ocorrer) ou elementos interativos (podem ocorrer em certa frequência). A teoria de Hasan reconhece, por meio das singularidades de contexto de (situação, registro e cultura) que é possível prever a estrutura de um texto. Interpretando a linguagem como ação social, como citado anteriormente, Hasan teoriza o gênero por meio da gramática sistêmico-funcional de Halliday.

A partir da Configuração Contextual (CC) de um texto é possível fazer previsões acerca da obrigatoriedade ou opcionalidade, assim como a possibilidade de interação e sequência dos elementos que o compõem, surgindo então a Estrutura Potencial do Gênero (EPG) a qual objetiva apresentar as possíveis estruturas esquemáticas de um texto em diferentes situações.

Muitos linguistas sistêmicos congregam conhecimento aos gêneros discursivos. A partir da linguística sistêmicofuncional, o conceito de registro se funde com o conceito de gênero. De acordo com Hemais e Biasi-Rodrigues (2005, p. 112) "registro é entendido como variação na linguagem, em que grupos de traços linguísticos são correlacionados com traços recorrentes em determinadas situações".

James Robert Martin adotou uma perspectiva teleológica para a análise de gêneros discursivos, definida a partir de várias teorias de diferentes autores. Segundo essa perspectiva o gênero se define como "um sistema estruturado em partes, com meios específicos para fins específicos". (Júnior \& Lima-Lopes, 2005, p. 29). Martin (1984, p. 25) define o gênero como "uma atividade direcionada por objetivos e propósitos realizada em estágios e na qual os falantes se engajam como membros de nossa cultura".

O gênero pode ser um versátil elemento que sofre modificações de acordo com os participantes, objetivos e situações comunicativas. De acordo com a teoria de Martin "o acesso de um falante ao gênero é mediado pelos diversos discursos das etnias, classes sociais, sexo, geração, dentre outros”. (Martin, 1992, p. 495).

Já a perspectiva discursivo-semiótica de Gunther Kress defende que os gêneros são cultural e historicamente variáveis, para ele os gêneros são "tipos de texto que codificam os traços característicos e as estruturas dos eventos sociais, bem como os propósitos dos participantes discursivos envolvidos naqueles eventos”. (Balocco, 2005, p. 65)

Torna-se relevante ressaltar que na visão de Kress, os gêneros discursivos devem ser estudados levando-se em conta a linguagem conjuntamente com os elementos não-verbais que o constituem. Essa perspectiva, segundo Balocco (2005, p. 65) apresenta-se como "um contraponto a teorias sobre gêneros textuais que restringem ao exame de seus recursos verbais, negligenciando o estudo dos diferentes sistemas de signos usados na construção de sentidos". 
A perspectiva sociorretórica, representada pela figura de John Swales surge em 1960 com o estudo de gênero em inglês para fins específicos (English for Specific Purposes - ESP). Esse panorama de estudo do gênero institui relação entre as tradições linguísticas e a retórica e define que:

Um gênero compreende uma classe de eventos comunicativos, cujos membros compartilham um dado conjunto de propósitos comunicativos. Esses propósitos são reconhecidos pelos membros especialistas da comunidade discursiva de origem e, portanto, constituem a base lógica para o gênero. Essa base molda a estrutura esquemática do discurso e influencia e coloca limites à escolha de conteúdo e de estilo. O propósito comunicativo é tanto um critério privilegiado como um critério que opera para manter o escopo de um gênero tal como aqui concebido, estritamente focado em uma ação retórica comparável. Além do propósito, os exemplares de um gênero exibem vários padrões de similaridade em termos de estrutura, estilo, conteúdo e audiência pretendida. Se todas as expectativas de probabilidade mais alta forem realizadas, o exemplar será visto como prototípico pela comunidade discursiva de origem. ${ }^{2}$ (Swales, 1990, p. 58)

Mesmo com o surgimento datado dos anos 60, a obra de John Swales (1990) foi pioneira, nela Swales "teorizou e desenvolveu de forma mais completa a metodologia para introduzir a análise de gêneros na pesquisa e no ensino de ESP". (Bawarshi \& Reiff, 2013, p. 61)

Sobre a ESP, Bawarshi e Reiff, de forma loquaz, afirmam:

inserido na categoria mais abrangente de língua para fins específicos, o inglês para fins específicos se concentra no estudo e ensino de variedades especializadas do inglês, na maioria das vezes voltados para falantes não nativos em contextos acadêmicos e profissionais avançados. (Bawarshi \& Reiff, 2013, p. 60)

Swales, preservou a relação do gênero e a utilização social da língua pensada por Bakhtin, porém em suas obras percebe-se uma aplicação direta aos gêneros discursivos em contextos acadêmicos e profissionais. A perspectiva da sociorretórica de Swales foi amplamente utilizada para o ensino de inglês para fins específicos (ESP) e diversa à visão de gênero de Bakhtin, ao invés do enunciado, Swales se volta para a estrutura organizacional e aspectos formais do texto.

Swales, pensando no ensino, formulou sua própria definição de gênero inspirado em quatro campos de estudos, sendo eles o campo dos estudos folclóricos, dos estudos literários, da linguística e da retórica. Os estudos de folclore, segundo Swales são importantes para a classificação do gênero, considerando tipos ideais de textos e não textos reais, assim enfoca as formas, que são permanentes, mas são alteradas pela "mudança no papel na sociedade”. (Hemais \& Biasi-Rodrigues, 2005, p. 111)

Já o campo dos estudos literários, ao contrário dos estudos de folclore, tem a não estabilidade destacada. $\mathrm{O}$ terceiro campo, forte influenciador dos estudos acerca dos gêneros discursivos é a linguística, que muitos linguistas por associarem a palavra "gênero" aos gêneros literários, demonstram grande resistência em adotá-lo.

O quarto e último campo que contribui para a análise de gêneros são os estudos da retórica. Swales, inspirado nesses quatro campos de estudo, criou a sua definição de gênero compreendendo classe de eventos e propósitos comunicativos partilhados. (Swales, 1990).

Ao definir evento comunicativo como aquele em que a linguagem tem papel significativo e indispensável, Swales afirma que os eventos comunicativos se tornam gêneros ao passo que há um conjunto de objetivos comunicativos.

Com a abordagem sociorretórica, Swales escreveu um artigo com a coautoria de Askehave e nele propõem um procedimento textual/linguístico onde o propósito comunicativo é estudado junto com a estrutura, estilo e conteúdo do gênero,

\footnotetext{
${ }^{2}$ Tradução nossa. No original: "A genre comprises a class of communicative events, the members of which share some set of communicative purposes. These purposes are recognized by the expert members of the parent discourse community, and thereby constitute the rationale for the genre. This rationale shapes the schematic structure of the discourse and influences and constrains choice of content and style. Communicative purpose is both a privileged criterion and one that operates to keep the scope of a genre as here conceived narrowly focused in comparable rhetorical action. In addition to purpose, exemplars of a genre exhibit various patterns of similarity in terms of structure, style, content and intended audience. If all high probability expectations are realized, the exemplar will be viewed as prototypical by the parent discourse community".
} 
e posteriormente redefinição e um procedimento contextual onde o processo comunicativo concebe a identificação da comunidade e peculiaridades do gênero. (Bawarshi \& Reiff, 2013, p. 70)

Segundo Hemais e Biasi-Rodrigues (2005, p. 109) Swales conserva uma abordagem baseada em uma análise linguística denotando aspectos da construção do texto por meio das práticas acadêmicas e profissionais pelas quais o texto se configura. Ainda segundo Hemais e Biasi-Rodrigues (2005, p. 109) para Swales "essa abordagem tem grande relevância para o ensino, visto que a conscientização linguística torna o ensino/aprendizagem mais eficaz". A integração das tradições de vários campos de estudos é uma marca da noção de gênero proposta por Swales.

Existem vários aspectos em que a abordagem de gênero em LSF e ESP são análogos, porém outros tantos em que se diferenciam. Uma semelhança entre elas é que ambas comungam:

a concepção fundamental de que os traços linguísticos estão ligados ao contexto e à função social. E ambas se orientam pelo imperativo pedagógico de tornar visível para estudantes desfavorecidos as conexões entre língua e função social incorporadas pelos gêneros. (Bawarshi \& Reiff, 2013, p. 62)

Tanto a abordagem de gênero em ESP quanto a abordagem em LSF pactuam com o propósito de que um ensino explícito de gêneros relevantes possibilita aos estudantes menos favorecidos, acesso a modos de comunicação. Conforme Hyland:

o ensino de gêneros chave é, consequentemente, um meio de ajudar os estudantes a obter acesso a modos de comunicação que já têm acumulado capital cultural em determinadas comunidades profissionais, acadêmicas e ocupacionais. Ao tornar visíveis e alcançáveis esses gêneros de poder, através do ensino explícito, as pedagogias de gênero buscam desmistificar os tipos de escrita que aumentarão as oportunidades de carreira dos estudantes e proporcionarão acesso a um leque maior de opções de vida. (Hyland, 2003, p. 24)

Apesar das abordagens de gênero LSF e ESP partilharem semelhanças, elas sutilmente se contrapõem de forma determinante quanto ao público-alvo de aplicação, fato esse que acarreta relevantes consequências na forma de perceber e analisar os gêneros. As abordagens de gênero da LSF normalmente tencionam, como público-alvo, crianças em idade escolar, que são econômica e culturalmente desfavorecidas, já as abordagens em ESP normalmente visam estudantes de pós-graduação, estrangeiros, falantes não-nativos de língua inglesa, geralmente desfavorecidos linguisticamente. (Bawarshi \& Reiff, 2013, p. 63)

Nos Estados Unidos, entre os anos de 1960 e 1970, a retórica clássica passou por um processo de reformulação e associada ao ensino de estratégias de persuasão, em um contexto de diminuição das distâncias entre os mundos clássico e moderno, novas teorias surgem originando a Nova Retórica. (Carvalho, 2005, p. 130).

Carolyn Miller elaborou uma abordagem na qual afirma que o estudo de gênero é valioso porque enfatiza alguns aspectos sociais e históricos da retórica que outras perspectivas não permitem.

A noção de gênero como ação social foi preconizada por Miller que juntamente com Swales e Bazerman tem se dedicado a criação de uma teoria de gênero, tal fato pode ser evidenciado, nas obras deses autores, pois estas possuem vários pontos em comum. Miller, Swales e Bazerman são integrantes da escola de estudos de gêneros norte-americana, fundamentalmente influenciada por antropólogos, sociólogos, etnógrafos e também por Bakhtin, na qual predomina o interesse pela natureza social do discurso. (Carvalho, 2005, p. 130)

Miller (1994) define o gênero como uma "ação retórica tipificada baseada em situações recorrentes" onde o gênero funciona como elo entre as produções e as instituições que, nos contextos sociais e nos atos de fala o produzem. (Miller, 1994, p. 24) 
De acordo com Miller (1984, p. 152) "a classificação de um discurso soará como retórica se contribuir para uma compreensão de como ele funciona, - isto é, se refletir a experiência retórica das pessoas que criam e interpretam o discurso"3.

$\mathrm{O}$ conceito de gênero desenvolvido por Miller tem como base a recorrência e a ação retórica, é focada no público, modos de pensamento e situações semelhantes. Apoiada em outros pensadores que também discutem os gêneros como ação social, Miller cria uma definição retoricamente válida de gênero, afirmando que esta precisa estar centrada na ação usada para sua realização. (Hoffnagel, 2012, p. 21)

Para uma teoria de gêneros o que é verdadeiramente importante nas situações retóricas, que são as interpretações que se faz das situações de interação social, é o fato de que elas são recorrentes, segundo Hoffnagel (2012, p. 29) "para entender a recorrência, é necessário rejeitar as tendências materialistas na teoria situacional". Logo, a recorrência é definida pelas situações recorrentes podendo apresentar uma tendência em mostrar ou minimizar as relações dialógicas entre um discurso e outro. Ainda, de acordo com Hoffnagel (2012, p. 29) "a recorrência é inferida por nossa compreensão de situações como, de alguma forma, "comparáveis", "similares", ou "análogas" a outras situações".

Focalizando seus estudos na retórica, na comunicação e em suas relações com tecnologia e ciência, Miller (1984, p. 151) vê o gênero como "uma ação retórica tipificada", sendo necessárias, para o entendimento desse conceito, as noções de motivação, intenções, situação retórica e contexto em que essas ações podem ser interpretadas.

Segundo Miller (1994, p. 36) o gênero está intimamente ligado ao discurso que é decorrente da ação retórica e passível de interpretação a partir das regras que o regulam; são formados pela soma de forma e substância, termo utilizado por Miller como sinônimo de conteúdo.

Segundo Marcuschi (2008, p. 153) nessa perspectiva de gênero "a atenção não se volta para o ensino e sim para a compreensão do funcionamento social e histórico, bem como sua relação com o poder". Miller tenta aliar a compreensão dos gêneros aos processos sociais e aos usos que faz da linguagem, assim, de acordo com Carvalho (2005, p. 133) "o gênero espelha a experiência de seus usuários" fazendo com que o texto concretize a experiência por meio da substância.

Bazerman (1994) assim como Miller, trabalha na perspectiva do gênero com ação social tipificada, porém sua abordagem é um pouco mais voltada ao aspecto linguístico. Bazerman foca sua teoria nas regularidades das situações recorrentes, levando em consideração as intenções sociais na forma e no conteúdo dos atos comunicacionais, sob a ótica dos usuários da língua.

Para a elaboração de sua noção de tipificação, Bazerman recorre aos conceitos de fato social que acometendo as opções discursivas do falante, assim como a força dos enunciados, refere-se ao que se acredita ser verdadeiro e constituído por meio da linguagem e nos atos de fala que podem ser classificados como sentenças que possuem significação. (Bazerman, 2005)

\section{Considerações Finais}

São notáveis os números pesquisas nas áreas da Linguística e da Linguística Aplicada com vistas a investigação acerca dos gêneros discursivos sob diferentes perspectivas teórico metodológicas. Esse artigo propôs um mapeamento das diferentes abordagens representadas por distintos autores como Hasan (1995) que, em suas investigações, teoriza o gênero por meio da gramática sistêmico-funcional de Halliday (1985), a qual compreende que a estrutura linguística está atrelada à função social e ao contexto. Outro representante da abordagem sociossemiótica, Martin (1992) elabora sua perspectiva teleológica para análise de gêneros discursivos remetendo-se ao trabalho de Halliday (1985) e Mathiesen (1995). Além de considerar seus

\footnotetext{
3 Tradução nossa. No original: A classification of discourse will be rhetorically sound if it contributes to an understanding of how discourse works, - that is, if it reflects the rhetorical experience of the people who create and interpret the discourse.
} 
trabalhos anteriores, Martin emprega o conceito de gênero elaborado por Bakhtin (1992) considerando-o uma atividade norteada pelos objetivos e propósitos comunicativos. Ainda sob uma abordagem sociossemiótica, na visão de Kress, os gêneros discursivos devem ser estudados levando-se em conta a linguagem conjuntamente com os elementos não-verbais que o constituem. Os três autores citados estudam os gêneros do discurso, considerando a linguagem como prática social, a partir da abordagem sociossemiótica que busca compreender a relação bidirecional entre discurso e estruturação social.

Representada pela figura de John Swales, a sociorretórica surge em 1960 com o estudo de gênero em inglês para fins específicos (English for Specific Purposes - ESP), oferecendo um panorama de estudo do gênero que institui relação entre as tradições linguísticas e a retórica. A LSF e ESP partilham semelhanças, mas elas sutilmente se contrapõem de forma determinante quanto ao público-alvo de aplicação, fato esse que acarreta relevantes consequências na forma de perceber e analisar os gêneros.

A perspectiva sociorretórica ainda possui Miller (1994) e Bazerman (2005) como expoentes, abordagem essa que considera os gêneros discursivos como ações sociais que representam uma classe de eventos que compartilham propósitos comunicativos, possuem lógica inata, traços e usos linguísticos específicos de acordo com a comunidade discursiva.

A escola de Sydney (perspectiva sistêmico-funcional) concentra-se em análises linguísticas de aspectos textuais, vendo o gênero como mais estável, já a escola norte-americana foca sua atenção nas relações entre texto e contexto e considera os gêneros mais dinâmicos.

Por fim, com a realização desta pesquisa acerca dos gêneros discursivos sob diferentes perspectivas teórico metodológicas, anseio que esta produção possa contribuir para pesquisas e implicações analíticas e pedagógicas, ajudando a embasar outros estudos que objetivem refletir acerca das múltiplas possibilidades de materialização da língua a partir dos gêneros discursivos.

O referido artigo possibilita concluir que há um leque de possibilidades de pesquisas acerca das diferentes perspectivas teórico metodológicas dos gêneros discursivos, logo realizar distintos estudos abordando as diferentes teorias de gênero e, posteriormente, publicá-las, apresenta-se como um fecundo espaço de produção do conhecimento nessa área.

\section{Referências}

Alves, M. A. (2011). Da hermenêutica filosófica à hermenêutica da educação. Acta Scientiarum, 33 (1), 17-28. 10.4025/actascieduc.v33i1.11265

Bakhtin, M. M. (1997). Estética da Criação Verbal. Martins Fontes.

Balocco, A. E. (2005). A perspectiva teleológica de Martin para a análise dos gêneros textuais. In: Meurer, J. L., Bonini, A. \& Motta-Roth, D. (org.). Gêneros teorias, métodos e debates. Editora Parábola.

Bawarshi, A. S., Reiff, M. J. (2013). Gênero: história, teoria, pesquisa, ensino. Editora Parábola.

Bazerman, C. (1994). Systems of genres and the Enactement of Social Intentions. In: Freedman, A. \& Medway, P. (orgs.). Genre and The New Rethoric. London: Taylor \& Francis.

Bazerman. C. (2005). Atos de fala, gêneros textuais e sistema de atividades: como os textos organizam atividades e pessoas. In: Dionísio \& Hoffnagel (Org.). Gêneros textuais, tipificações e interações. Cortez.

Berger, P. L. \& Luckmann, T. (2003). Os fundamentos do conhecimento na vida cotidiana. A construção social da realidade. Vozes.

Carvalho, G. (2005). Gênero como ação social em Miller e Bazerman: o conceito, uma sugestão metodológica e um exemplo de aplicação. In: Meurer, J. L., Bonini, Adair \& Motta-Roth, Désirée (org.). Gêneros teorias, métodos e debatesEditora Parábola.

Dell'isola, R. L. P. (2007). Retextualização de gêneros escritos. Lucerna.

Eggins, S. (2004). An introduction to systemic functional linguistics. Continuum.

Gil, A. C. (2002). Como elaborar projetos de pesquisa. Atlas, p. 45.

Halliday, M. A. K. (1985). An Introduction to Functional Grammar. Edward Arnold.

Halliday, M. A. K. \& Hasan, R. (1989). Language, Context and Text: Aspects of Language in a Social-Semiotic Perspective. Oxford Univerity Press. 
Research, Society and Development, v. 10, n. 2, e44810212718, 2021

(CC BY 4.0) | ISSN 2525-3409 | DOI: http://dx.doi.org/10.33448/rsd-v10i2.12718

Hasan, R. (1995). The Conception of Context in Text. In Fries, P., Gregory, M. (org.). Discourse in Society: Sistemic Functional Perspectives. Meaning and Choice in Language: Studies for Michael Halliday. Ablex.

Hemais, B. \& Biasi-Rodrigues, B. (2005). A proposta sociorretórica de John M. Swales para o estudo de gêneros textuais. In: Meurer, J. L., Bonini, Adair \& Motta-Roth, Désirée (org.). Gêneros teorias, métodos e debates. Editora Parábola.

Hoffnagel, J. (2012). Gênero textual, agência e tecnologia: estudos. Gênero como ação social. Parábola Editorial.

Hyland, K. (2003). Genre-Based Pedagogies: A Social Response to Process. Journal of Second Language Writing 12, China.

Júnior, O. V. \& Lima-Lopes, R. E. (2005). A perspectiva teleológica de Martin para a análise dos gêneros textuais. In: Meurer, J. L., Bonini, A., Motta-Roth, D. (org.). Gêneros teorias, métodos e debates. Editora Parábola.

Kress, G. Leite-Garcia, R. \& Van leeuwen, T. (1997). Discourse Semiotics. In: Van Dijk, T. A. (org.). Discourse as Social Interaction. Sage.

Lüdke, M., André, M.E.A. (1986). Pesquisa em educação: abordagens qualitativas. EPU.

Marcuschi, Luiz Antonio. (2008). Produção textual, análise de gêneros e compreensão. Parábola Editorial.

Martin, J. R. (1992). English Text: Systems and Structure. Philadelphia, John Benjamins Publishing Company.

Martin, J.R. (1984). Language, register and genre. In: Cristie, F. Language studies: children's writing: reader. Deakin University Press.

Miller, C. R. (1984). Genre as social action. Quarterly Journal of Speech, 1984.

Miller, C. R. (1994). Rethorical Community: The Cultural Basis of Genre. In: Freedman, A., Medway, P. (org). Genre and the New Rethoric. Taylor \& Francis.

Motta-Roth, D. \& Heberle, V. M. (2005). O conceito de "estrutura potencial de gênero" de Ruqayia Hasan. In: Meurer, J. L., Bonini, A., Motta-Roth, D. (org.). Gêneros teorias, métodos e debates. Editora Parábola

Pereira, A. S. et al. (2018) Metodologia da Pesquisa Científica. UFSM. https://www.ufsm.br/app/uploads/sites/358/2019/02/Metodologia-da-PesquisaCientifica_final.pdf

Pradanov, C. C. \& Freitas, E. C. (2013). Metodologia do trabalho científico: métodos e técnicas da pesquisa e do trabalho acadêmico. Feevale. http://www.feevale.br/Comum/midias/8807f05a-14d0-4d5b-b1ad-1538f3aef538/Ebook\%20Metodologia\%20do\%20Trabalho\%20Cientifico.pdf.

Swales, J. M. (1990). Genre Analysis: English in Academic and Research Settings. Cambridge University Press. 